\title{
LETTERS
}

\section{Snowfall and myocardial infarction. What is the effect of barometric pressure?}

The study by Auger and colleagues in CMAJ showed that the amount and duration of snowfall was associated with an increased risk of admission to hospital and death due to myocardial infarction (MI) among men from Quebec, Canada. ${ }^{1}$ The study apparently did not adjust by barometric pressure; if the data are available, does the inclusion of barometric pressure have a confounding effect or effect modification on the estimates? Some studies have shown that changes in barometric pressure are associated with $\mathrm{Ml}$ and coronary deaths..$^{2-4}$

In the historic snowstorm that hit the eastern United States in January of 1978, barometric pressure in some cities dropped as low as 40 millibars in 24 hours. A blizzard is distinctive because of the fast drop in barometric pressure in a 24-hour period. Three days after the storm of 1978 , admissions for MI, total mortality and ischemic heart disease deaths increased in
Rhode Island for the five-day period following the blizzard; however, the effect of barometric pressure was not assessed in that study and the blizzard was considered the only culprit. ${ }^{5}$

A recent Asiatic study found that extreme ambient temperatures were associated with cardiorespiratory mortality. An interesting finding was the decrease of cold effect on mortality by $2.36 \%$ associated with an increase in barometric pressure, indicating that it may have an impact on the effect of other weather variables on mortality. ${ }^{6}$ Furthermore, there is evidence of a positive correlation between barometric pressure and blood oxygen saturation. ${ }^{7}$ Patients with $\mathrm{MI}$ or ischemic heart disease are particularly susceptible to changes in blood oxygen saturation.

\section{Eduardo Hernández-Garduño MHSc}

Physician epidemiologist, Unidad de

Investigación Básica Aplicada (UIBA), Centro Oncológico Estatal (COE), Instituto de Seguridad Social del Estado de México y Municipios (ISSEMYM), Toluca, México
Cite as: CMAJ 2017 April 18;189:E576. doi: $10.1503 / \mathrm{cmaj} .732928$

\section{References}

1. Auger N, Potter BJ, Smargiassi A, et al. Association between quantity and duration of snowfall and risk of myocardial infarction. CMAJ 2017;189:E235-42.

2. Danet S, Richard F, Montaye M, et al. Unhealthy effects of atmospheric temperature and pressure on the occurrence of myocardial infarction and coronary deaths. A 10-year survey: the Lille-World Health Organization MONICA project (Monitoring trends and determinants in cardiovascular disease). Circulation 1999;100:E1-7.

3. Goerre S, Egli C, Gerber S, et al. Impact of weather and climate on the incidence of acute coronary syndromes. Int J Cardiol 2007;118:36-40.

4. Ohlson CG, Bodin L, Bryngelsson IL, et al. Winter weather conditions and myocardial infarctions. Scand J Soc Med 1991;19:20-5.

5. Faich G, Rose R. Blizzard morbidity and mortality: Rhode Island, 1978. Am J Public Health 1979;69:1050-2.

6. Chung Y, Lim YH, Honda Y, et al. Mortality related to extreme temperature for 15 cities in Northeast Asia. Epidemiology 2015;26:255-62.

7. Pope CA III, Dockery DW, Kanner RE, et al. Oxygen saturation, pulse rate, and particulate air pollution: a daily time-series panel study. $\mathrm{Am} \mathrm{J}$ Respir Crit Care Med 1999;159:365-72.

Competing interests: None declared. 